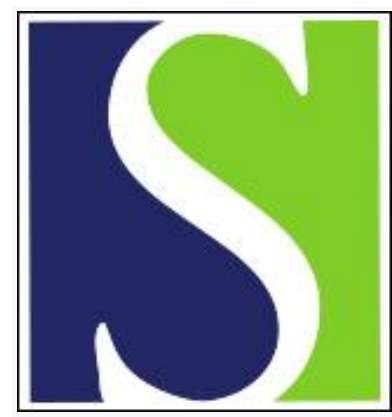

Scand J Work Environ Health 2020;46(4):382-391

https://doi.org/10.5271/sjweh.3883

Published online: 13 Jan 2020, Issue date: 01 Jul 2020

Risk of being granted disability pension among incident cancer patients before and after a structural pension reform: A Danish population-based, matched cohort study

by Pedersen P, Aagesen M, Tang LH, Bruun NH, Zwisler A-D, Stapelfeldt CM

In January 2013, a structural reform of the Disability Pension Act was implemented in Denmark with the purpose of reducing the number of granted disability pensions, in particular among individuals younger than 40 years. The study results confirm that purpose also among cancer patients. The personal implications of the reform among cancer patients are unknown and should be further explored.

Affiliation: DEFACTUM, Social \& Health Services and Labor Market, P.P. Oerums Gade 11, Building 1B, 8000 Aarhus C, Denmark. chrstp@rm.dk

Refers to the following text of the Journal: 2013;39(1):76-87

The following article refers to this text: 2021;47(3):224-232

Key terms: cancer; cohort study; Denmark; disability; disability pension; pension; pension reform; quality of life; return to work; vocational rehabilitation

This article in PubMed: www.ncbi.nlm.nih.gov/pubmed/31930408

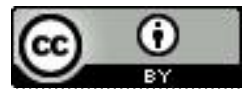




\title{
Risk of being granted disability pension among incident cancer patients before and after a structural pension reform: A Danish population-based, matched cohort study
}

\author{
by Pernille Pedersen, PhD, ${ }^{1,2}$ Maria Aagesen, MSc, ${ }^{3}$ Lars Hermann Tang, PhD, ${ }^{3,4}$ Niels Henrik Bruun, MSc, ${ }^{5}$ Ann-Dorthe Zwisler, \\ PhD, ${ }^{3}$ Christina M Stapelfeldt, PhD ${ }^{1,2}$
}

\begin{abstract}
Pedersen P, Aagesen M, Tang LH, Bruun NH, Zwisler A-D, Stapelfeldt CM. Risk of being granted disability pension among incident cancer patients before and after a structural pension reform: A Danish population-based, matched cohort study. Scand J Work Environ Health. 2020;46(4):382-391. doi:10.5271/sjweh.3883
\end{abstract}

\begin{abstract}
Objective This study aimed to examine the risk of being granted a disability pension (DP) among incident cancer patients up to five years after diagnosis compared to a match control group, before and after the structural reform of the Danish Disability Pension Act in 2013.
\end{abstract}

\begin{abstract}
Methods All 20-60-year-old incident cancer-diagnosed individuals from 2000 to 2015 were identified in the Danish Cancer Registry. A control group, not previously diagnosed with cancer, was identified in Statistics Denmark matched by gender, age, education, and household income. Risk differences (RD) in cumulative incidence proportions of being granted a DP between cancer patients and controls were analyzed before and after the reform.

Results In total, 111773 incident cancer patients and 506904 controls were included in the study. Before reform 10561 cancer patients and 11231 controls were granted DP; and 2570 cancer patients and 2646 controls were granted DP after the reform. The adjusted RD of being granted DP was significantly higher for cancer patients versus controls at all time points before the reform. The RD increased the most during the first (RD 3.6, 95\% CI 3.5-3.7) and second (RD 7.2, 95\% CI 7.0-7.4) follow-up year and levelled off the remaining three years. After the reform, the adjusted RD were lower for all 1-5 follow-up years compared to before the reform (RD range 2.8-7.7, 95\% CI 2.6-8.1).
\end{abstract}

Conclusion The 2013 reform of the Disability Pension Act reduced the risk of cancer patients being granted DP. The impact on a personal level should be further explored.

Key terms Denmark; Disability Pension Act; quality of life; return to work; vocational rehabilitation.

In the Nordic countries, $37 \%$ of all patients diagnosed with cancer are of working age, ie, 2-64 years (1). The possibility to engage in paid work is in general an important contributor to quality of life also for the increased prevalence of working-age cancer survivors as it restores identity and feelings of normality and solves financial concerns $(2,3)$. Hence, the motivation to return to work is high (4) and reflected in an average of $60 \%$ (range $24-94 \%$ ) of all cancer survivors actually returning to work (5). However, the lower range of return-to-work (RTW) successes implies that cancer survivors may face complications and disabilities that call for vocational rehabilitation (6).
Between 1980 and 2001, the risk of early retirement pension was $55-60 \%$ higher among Danish cancer patients compared to a matched control group (7). Since then, the focus on vocational rehabilitation for this group has grown both nationally $(8,9)$ and internationally $(10)$.

In the framework presented by Labriola (11), legislation is illustrated as a structural factor that overall tries to support individuals in their attempt to recover and return to work. In the Nordic welfare model, a generous benefit system offers financial security to sickness absentees who are unable to work. In cases of permanent work disability that inhibits work attendance, pensions are available. However, life courses have changed in the

1 Section for Clinical Social Medicine and Rehabilitation, Department of Public Health, Aarhus University, Aarhus C, Denmark.

2 DEFACTUM, Social \& Health Services and Labor Market, Central Region Denmark, Aarhus C, Denmark.

3 Knowledge Centre for Rehabilitation and Palliative Care, University of Southern Denmark and Odense University Hospital, Denmark.

4 Departmennt of Rehabilitation and Nutrition, Faculty of Health and Technology, Metropolitan University College, Copenhagen, Denmark.

5 Unit of Clinical Biostatistics, Aalborg University Hospital, Aalborg, Denmark. 
last century, moving toward a shorter work career due to more time spent on education before entering the workforce and an earlier retirement age. Compounded by the demographic development towards aging populations, countries can no longer afford their current social benefit schemes and must introduce reforms that increase retirement age and facilitate an inclusive labor market allowing people with $<100 \%$ work ability to participate (12). It is expected that the prevalence of chronic diseases will increase within an aging and inclusive workforce, which may in turn increase sick leave levels and lower productivity (13). In Austria, the retirement age was postponed by approximately two and three years for men and women, respectively (14), which in fact increased employment. However, spillover effects were seen especially in an increase in unemployment benefits, although disability insurance claims were largely unaffected. In Sweden, a social insurance reform was introduced in 2008 that decreased entitlement to sickness benefits and disability pension (DP) (15). Overall, a reduced number of individuals were granted sickness benefits and DP in 2011 versus 2004, but more went on statutory and employment pensions. Another Swedish study investigated the 1995-2010 sick leave rate among employees aged $\geq 65$ years (16). Even though the prevalence of $\geq 65$ year old employees increased within this timeframe, sick leave rates were lower in 2010 than in 1995.

In January 2013, a reform of the Danish Disability Pension Act was introduced that aimed to reduce the number of granted DP, in particular among persons $\leq 40$ years (17). The background for introducing this reform was an increasing incidence of granted DP especially to young individuals due to mental causes. The ideology behind the reform was to send a clear signal to young adults that they are not being abandoned and forgotten but supported and offered rehabilitation to improve their quality of life and ability to contribute to society. The reform also introduced multidisciplinary rehabilitation teams within each municipality to initiate rehabilitation efforts for these young adults at risk of being marginalized. The impact of this reform for cancer patients has not previously been studied, and to our knowledge no other studies on DP reforms targeted at primarily young adults have been studied.

As presented in the framework by Labriola (11), several factors related to personality trait, health, and the work environment have been identified as risk factors for DP. In the Danish register-based study by Carlsen et al (7), granted DP were more frequently seen among incident lymphomas and prostate and ovary cancers. Moreover, old age (18), unemployment, and long-term sick leave also influence work termination $(19,20)$. Incident cancer patients are in general more comorbid than the background population (21), which may affect their work ability and thus increase the risk of premature exit from the labor market (22). Ethnic minority groups have a higher cancer incidence and poorer survival rates than the majority group in western developed countries (23). Moreover, work conditions for low income and low-level educational jobs have been hypothesized as an explanation for the social inequality in cancer survivors permanent withdrawal from the labor market (24).

From the perspective of the dynamics of work disability prevention, it is therefore important to study, when taking other risk factors into account, how a structural reform affected incident cancer patients' labor market prospects. Thus, this study examined the risk of being granted a DP among incident cancer patients up to five years after diagnosis compared with a matched control group, before and after a 2013 structural reform of the Danish Disability Pension Act.

\section{Methods}

\section{Study population}

All incident first-time cancer-diagnosed individuals aged 20-60 years in the period January 2000 to December 2015 were identified in the Danish Cancer Registry (CAR) (25) along with date of diagnosis. Since 1943, all incident cancers have been registered in CAR. Only diagnoses categorized according to Nordic cancer statistics (NORDCAN) were included. Thus, non-melanoma skin cancer was excluded as documentation of this condition is considered heterogeneous and incomplete (26).

A control group was identified in Statistics Denmark in 1:5 ratio matched on gender, age (ten-year age strata), highest completed education (primary/high school, vocational education, education $<3$ years, bachelor degree, and master degree), and household income ( $\leq$ -60 395, -60 394- -20 132, -20 131- -1, 0-20 131, $20132-40263,40264-60394, \geq 60395$ euros), defined at the time of diagnosis for the cancer patient. The matched controls had not previously been diagnosed with cancer except for non-melanoma skin cancer.

To ensure that the controls were indeed cancer free, CAR provided the personal identity number to Statistics Denmark of all Danes who, prior to 2000, had a cancer diagnosis. Thus being registered in CAR prior to 2000 prohibited an individual from being eligible as a control.

Matched controls were assigned the same baseline date as the diagnosis date of the cancer patient.

\section{Data sources and procedures}

For both the cancer patients and controls, a unique personal identification number assigned to every Danish resident enabled linkage of information from multiple regis- 
ters: CAR (25), Statistics Denmark, the Danish National Patient Register (DNPR) (27), and the Danish Register for Evaluation of Marginalization (DREAM) (28).

\section{Outcome measures}

The cumulative incidence proportion (CIP) of granted DP was measured from baseline and up to a maximum of five years' follow-up. Information about DP was identified in DREAM, which records all social transfer payments on a weekly basis and encompasses information from July 1991 to the present (29). The granting of DP is registered in that particular week where the beneficiary receives the pension and will continue to do so until old age pension, emigration or death occurs. Thus three types of events were treated as competing risks in the analyses.

Data from DREAM has previously been validated against workplace-registered data on sick leave $(28,30)$ and self-reported information on type of income (28), and both studies found that DREAM provides valid data.

\section{Potential confounders}

Ethnicity was identified in DREAM and categorized as Danish, Western (except Danish), and non-Western.

Comorbidity was based on the Charlson Comorbidity Index (CCI) for a period of five years prior to baseline (31-33). The DNPR provided data on 19 selected somatic comorbidities, scored on a 3-point severity scale to create the CCI, which was then categorized as $0,1-2$ and $\geq 3$.

Long-term sickness absence ( $\geq 4$ weeks) 12-24 months prior to baseline was identified in DREAM and based on weeks with sickness benefits and reported in three categories ( $0,1-26$ and 27-52 weeks). A 12-month wash out period presiding cancer diagnosis was chosen due to potential confounding from reduced workability one year before the cancer diagnosis (34).

\section{Statistical analyses}

The frequencies of matching variables and potential confounders were reported for the cancer and control populations. For descriptive purposes only, the cancer diagnoses were reported and categorized according to NORDCAN [breast, upper-gastro-and-intestines (UPGI), melanoma skin, colorectal, male genitals, lung, gynecological, brain and central nervous system (CNS), blood, kidney and bladder, other] (26).

The CIP of granted DP was counted between baseline and up to 1-5-year follow-up for the cancer and the control groups. Differences in CIP between the cancer and control groups were interpreted as risk differences (RD) and pseudo observations in generalized linear regressions were used for estimation $(35,36)$.
Entry was defined as the date of cancer diagnosis for the incident cancer patients and their matched controls accordingly. The end of follow-up was defined by the week where DP was granted, the occurrence of competing risks (old age pension, emigration or death) or end of 1-5-year follow-up, which ever occurred first.

During follow-up in the present study, the Danish Disability Pension Act was reformed in January 2013, by which individuals aged $\leq 40$ years in principle no longer could be granted a DP. To account for the reform, delayed entry was applied for cancer patients diagnosed before January 2013 and still at risk of being granted DP by January 2013 and onwards. Adjusted for matching variables, crude and adjusted RD were presented.

To assess whether RD significantly changed following the reform, RD were subtracted (after minus before 2013) and 95\% confidence intervals (CI) were calculated by the corresponding RD standard errors.

Moreover, 5-year CIP for the cancer population and $\mathrm{RD}$ stratified on the matching variables were estimated.

The significance level was set at $\mathrm{P}<0.05$. STATA version 15.1 (StataCorp, College Station, Texas, USA) was used as statistical software.

\section{Ethics}

The Danish Data Protection Agency approved this study (1-16-02-445-16). According to Danish law, approval from the Danish National Committee on Biomedical Research Ethics was not needed as this is only provided for projects using biological material or involving biomedical treatment. All procedures performed in studies involving human participants were in accordance with the ethical standards of the institutional and/or national research committee and with the 1964 Helsinki Declaration and its later amendments or comparable ethical standards (37).

\section{Results}

A total of 219694 20-60-year-old individuals were identified in CAR between 2000 and 2015, and 1094399 controls were identified in the matching procedure. Of those, 83275 (38\%) cancer patients were excluded; primarily due to non-cancer diseases (ie, precancerous lesions) and non-melanoma skin cancer diagnosis. That resulted in an exclusion of $412312(38 \%)$ matched controls. In total, 111773 incident cancer patients and 506904 matched controls met the inclusion criteria and were included in the study and followed for up to five years (figure 1).

More 50-60-year-olds were present in the cancer $(58.0 \%)$ than control $(55.8 \%)$ population. Also, more cancer patients than controls had primary or high 
school as their highest achieved education and earned $€ 0-20131$ per year (table 1). More ethnic Danes were diagnosed with cancer than western and non-western residents. Cancer patients had more comorbidity the presiding five years before cancer diagnosis and spend more time on sick leave during the year prior to the wash-out period than the controls. Breast and UPGI cancer were the most incident cancer types, whereas kidney and bladder as well as other cancers had the lowest incidence (table 1).

During the five years follow-up before the reform a total of 10561 cancer patients were granted DP and 41718 controls. The adjusted RD of being granted a DP for cancer patients was significantly higher than the controls at all time points (table 2). The RD of granted pensions between the controls and cancer patients were most pronounced within the first and second follow-up year (RD 3.60, 95\% CI 3.46-3.74 and RD 7.20, 95\% CI 7.01-7.40, respectively) and levelled off the remaining three years.

After the reform, 2570 and 2646 cancer patients and controls were granted DP, respectively. The CIP of being granted a disability pension for cancer patients were lower for all follow-up years than before the reform, ranging from $3.09 \%(95 \%$ CI $2.85-3.33)$ within the first year to $9.28 \%$ (95\% CI 8.91-9.66) within the five years follow-up (table 2). The adjusted RDs were statistically significantly smaller after 2013 than before, ranging from RD difference -0.78 (95\% CI -1.02- -0.50$)$ to RD difference -2.05 (95\% CI -2.51- -1.59) (table 2).

Within the first three follow-up years, the stratified analyses showed a tendency of higher RD between con- trol and cancer men than women granted DP. Within the remaining two follow-up years, this difference levelled off (table 3 ). After the reform, the difference between men and women remained throughout the five years but at a lower level than before 2013. The younger the age, the smaller the RD observed - both before and after the reform. For those $<40$ years, the $\mathrm{RD}$ were approximately halved after the reform compared to before. For the age groups $>39$ years, a reduction in $\mathrm{RD}$ was seen after the reform but less pronounced than for those $<40$ years. For the 50-60-year-old group, the RD remained the same after the reform from the second until the fifth follow-up year up (table 3). The reform seemed to reduce the difference in RD for those with the highest achieved educational level and annual income. Whereas for the loweducated and small-income groups, the reduction in $\mathrm{RD}$ after the reform were much smaller than for the more socioeconomically fortunate. For those with a negative yearly income, the tendencies departed somewhat for the low socioeconomical groups and were more comparable with the well-educated and high-income groups.

Focusing solely on the cancer population, the CIP of being granted a DP within the five-year follow-up period were reduced after the reform for all matching variables compared with the CIP before the reform. Unlike the reductions in $\mathrm{RD}$ after the reform, the reductions in CIP were not particularly associated with the different levels of the various matching variables. The smallest reduction in CIP $(8.98-8.52=0.46 \%$ points $)$ was observed for the -€20 131- -1 income-strata and the highest was observed for the 40-49-year age-strata $(13.26-6.85=$ $6.41 \%$ points) (table 3 ).
Figure 1. Flow chart of the exclusion process from initial to final study sample.

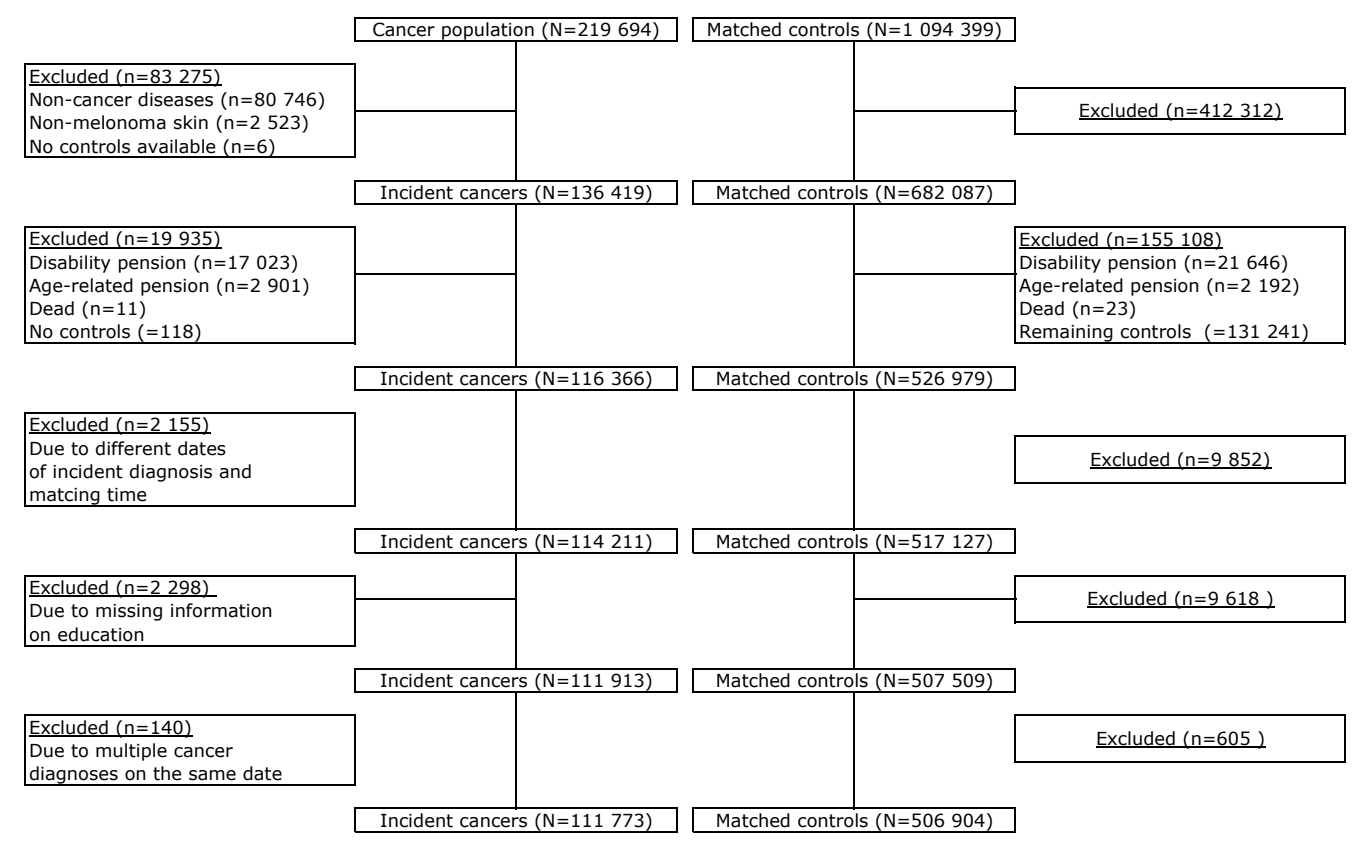




\section{Discussion}

This Danish population-based study compared the CIP of being granted a DP among incident cancer patients up to five years after diagnosis, before and after a structural reform of the Danish Disability Pension Act in January 2013. Overall, we found the RD between controls and cancer patients of being granted a DP were reduced after 2013. This was especially the case for socioeconomically fortunate groups. For the cancer group, the CIPs were overall reduced after the reform and these reductions were less dependent of socioeconomic variables than among the controls.

Labriola's Dynamic Work Disability Model (11) proposed different factors that may affect pathways leading to RTW or termination of work, representing the two possible extremes in the model. Structural factors such as legislation are illustrated as a RTW-promoting mechanism (11). The overall purpose of the 2013 structural reform of the Disability Pension Act was to reduce the number of granted DP in particular among 18-40-yearolds (17). As our findings showed an overall reduced risk of being granted DP among cancer patients after (versus before) 2013, municipal social workers responsible for the granting of DP seem to have translated the legislation according to the intension of the reform, ie, in favor of vocational rehabilitation. However, as the risks were reduced irrespective of gender, age, education and income among the cancer patients within the five-year follow-up, it may point toward a generally decreased disability among cancer survivors and thereby a reduced need for permanent withdrawal from the labor market. However, improvements in early diagnosis and treatments are mentioned as factors responsible for reduced mortality rates (38), whereas the increased prevalence of cancer survivors may experience increased levels of comorbidity, physical, and mental late effects that may reduce work ability (39). Looking at the reductions in RD from before to after 2013, the results pointed in different directions. On one hand, cancer patients were still more likely to be granted DP than controls but, on the other hand, this had also to do with increased risks of DP among the controls depending on their socioeconomic status. The introduction of municipal rehabilitation teams has put emphasis on vocational rehabilitation in general; social workers may be more aware of offering other public benefits than DP targeted to sustain work ability and employability. This is in line with experiences gained from the introduction of social reforms in other countries, where spill-over effects were observed such as increased unemployment rates when retirement age was postponed (14) and an increase of statutory pensions were seen when the entitlement to DP and sickness benefits was reduced (15). It may be an indication
Table 1. Matching variables and baseline characteristics of the study population.

\begin{tabular}{|c|c|c|c|}
\hline & $\begin{array}{c}\text { Cancer } \\
\mathrm{N}=111773\end{array}$ & $\begin{array}{c}\text { Controls } \\
\mathrm{N}=506904\end{array}$ & $\begin{array}{c}\text { Total } \\
\mathrm{N}=618677\end{array}$ \\
\hline & $\mathrm{N}(\%)$ & $\mathrm{N}(\%)$ & $\mathrm{N}(\%)$ \\
\hline \multicolumn{4}{|l|}{ Age-matching group } \\
\hline $20-29$ & $5658(5.1)$ & $27938(5.5)$ & $33596(5.4)$ \\
\hline $30-39$ & $13124(11.7)$ & $63835(12.6)$ & 76959 (12.4) \\
\hline $40-49$ & $28193(25.2)$ & $132440(26.1)$ & $160633(26.0)$ \\
\hline $50-60$ & $64798(58.0)$ & 282691 (55.8) & 347489 (56.2) \\
\hline \multicolumn{4}{|l|}{ Gender-matching group } \\
\hline Female & $62405(55.8)$ & $281720(55.6)$ & $344125(55.6)$ \\
\hline Male & $49368(44.2)$ & $225184(44.4)$ & $274552(44.4)$ \\
\hline \multicolumn{4}{|l|}{ Education-matching group } \\
\hline Primary \& high school & 32234 (28.8) & $132123(26.1)$ & $164357(26.6)$ \\
\hline Vocational education & $45218(40.5)$ & $209344(41.3)$ & $254562(41.2)$ \\
\hline Short further education & $5295(4.7)$ & $25355(5.0)$ & $30650(5.0)$ \\
\hline Bachelor education & $20770(18.6)$ & $99661(19.7)$ & $120431(19.5)$ \\
\hline $\begin{array}{l}\text { Long further education } \\
\text { \& research }\end{array}$ & $8295(7.4)$ & $40421(8.0)$ & $48677(7.9)$ \\
\hline \multicolumn{4}{|c|}{ Income-matching group (euros) } \\
\hline$\leq-60395$ & $70(0.1)$ & $339(0.1)$ & $409(0.1)$ \\
\hline$-60394--20132$ & $176(0.2)$ & $861(0.2)$ & $1037(0.2)$ \\
\hline$-20131--1$ & $1517(1.4)$ & $7426(1.5)$ & $8943(1.5)$ \\
\hline $0-20131$ & $28672(25.7)$ & $113460(22.4)$ & $142132(23.0)$ \\
\hline $20132-40263$ & 64034 (57.3) & $299177(59.0)$ & $363211(58.7)$ \\
\hline $40264-60394$ & $13198(11.8)$ & 65237 (12.9) & 78435 (12.7) \\
\hline$\geq 60395$ & $4106(3.7)$ & $20404(4.0)$ & $24510(4.0)$ \\
\hline \multicolumn{4}{|l|}{ Ethnicity } \\
\hline Danish & 103841 (92.9) & 461910 (91.1) & $565751(91.5)$ \\
\hline Western & $3020(2.7)$ & $15217(3.0)$ & $18237(3.0)$ \\
\hline Non-western & 3660 (3.3) & $24389(4.8)$ & $28049(4.5)$ \\
\hline Unknown & $1252(1.1)$ & $5388(1.1)$ & $6640(1.1)$ \\
\hline \multicolumn{4}{|l|}{ Comorbidity 5 years before } \\
\hline 0 & 103006 (92.2) & 481912 (95.1) & $584918(94.5)$ \\
\hline $1-2$ & $7771(7.0)$ & $22808(4.5)$ & $30579(4.9)$ \\
\hline$\geq 3$ & $996(0.9)$ & $2184(0.4)$ & $3180(0.5)$ \\
\hline \multicolumn{4}{|l|}{$\begin{array}{l}\text { Sick leave } 2 \text { years before } \\
\text { index date (weeks) }\end{array}$} \\
\hline 0 & $93930(84.0)$ & 433626 (85.5) & $527556(85.3)$ \\
\hline $1-26$ & 15419 (13.8) & $64121(12.7)$ & $79540(12.9)$ \\
\hline $27-52$ & $2424(2.2)$ & $9157(1.8)$ & $11581(1.9)$ \\
\hline \multicolumn{4}{|l|}{ NORDCAN cancer site } \\
\hline Breast & $23550(21.1)$ & & \\
\hline Upper-gastro, intestines & $11968(10.7)$ & & \\
\hline Melanoma skin & $11913(10.7)$ & & \\
\hline Colorectal & $9958(8.9)$ & & \\
\hline Male genitals & $9905(8.9)$ & & \\
\hline Lung & $8359(7.5)$ & & \\
\hline Gynaecological & $8219(7.4)$ & & \\
\hline Central nervous system & $8167(7.3)$ & & \\
\hline Blood & 8069 (7.2) & & \\
\hline Kidney \& bladder & $6403(5.7)$ & & \\
\hline Other & $5262(4.7)$ & & \\
\hline
\end{tabular}

of a fulfillment of the reform's overall purpose, namely to increase attachment to the labor market, and thus supporting the assumptions put forward in Labriola's conceptual framework (11). It is, however, important to further investigate if the reform merely maintains individuals on social benefits, other than DP, with no work prospects. From 2013 until the present, an increased CIP of granted DP has been observed in Denmark. This may be a delayed effect of initiated rehabilitation efforts that ultimately did not reveal any work ability (38-40).

Along with the reform, regulations of the employment scheme for partly work-disabled (flexi-job) were 
Table 2. Risk differences (RD) in cumulated incidence proportions (CIP) of being granted disability pensions before and after January 2013 (time of structural reform). [Cl=confidence interval.]

\begin{tabular}{|c|c|c|c|c|c|c|c|c|}
\hline & \multicolumn{2}{|c|}{ Cancer } & \multicolumn{2}{|c|}{ Non-cancer } & \multirow{2}{*}{$\begin{array}{c}\text { Cancer } \\
\text { CIP } \\
\%(95 \% \mathrm{Cl})\end{array}$} & \multicolumn{2}{|c|}{$\mathrm{RD}$} & \multirow{2}{*}{$\begin{array}{l}\text { RD difference } \\
\text { after-before } \\
(95 \% \mathrm{Cl})^{\mathrm{c}}\end{array}$} \\
\hline & $\begin{array}{l}\text { Disability } \\
\text { pensions }\end{array}$ & $\begin{array}{c}\text { Competing } \\
\text { risk }^{\mathrm{a}}\end{array}$ & $\begin{array}{l}\text { Disability } \\
\text { pensions }\end{array}$ & $\begin{array}{c}\text { Competing } \\
\text { risk }^{\mathrm{a}}\end{array}$ & & $\%(95 \% \mathrm{Cl})^{b}$ & $\%(95 \% \mathrm{Cl})^{\mathrm{c}}$ & \\
\hline \multicolumn{9}{|c|}{ Before reform } \\
\hline Year 0-1 & 3829 & 6364 & 2704 & 11769 & 4.47 (4.33-4.61) & $3.63(3.49-3.77)$ & $3.60(3.46-3.74)$ & \\
\hline Year 0-2 & 7349 & 14356 & 5261 & 17260 & $8.87(8.67-9.06)$ & $7.21(7.02-7.41)$ & $7.20(7.01-7.40)$ & \\
\hline Year 0-3 & 8944 & 23522 & 7628 & 20374 & $11.03(10.81-11.24)$ & $8.58(8.36-8.79)$ & $8.57(8.35-8.79)$ & \\
\hline Year 0-4 & 9933 & 32486 & 9573 & 22678 & $12.54(12.31-12.78)$ & $9.37(9.14-9.6)$ & $9.37(9.14-9.61)$ & \\
\hline Year 0-5 & 10561 & 41718 & 11231 & 24928 & $13.55(13.31-13.79)$ & $9.71(9.46-9.96)$ & $9.73(9.48-9.97)$ & \\
\hline \multicolumn{9}{|c|}{ After reform } \\
\hline Year 0-1 & 696 & 993 & 368 & 2172 & 3.09 (2.85-3.33) & $2.80(2.56-3.05)$ & $2.82(2.57-3.06)$ & $-0.78(-1.06--0.50)$ \\
\hline Year 0-2 & 1496 & 3076 & 875 & 3906 & $5.90(5.58-6.21)$ & $5.29(4.97-5.61)$ & $5.33(5.01-5.65)$ & $-1.87(-2.24--1.50)$ \\
\hline Year 0-3 & 2001 & 6101 & 1440 & 5148 & $7.48(7.14-7.82)$ & $6.55(6.20-6.89)$ & $6.59(6.24-6.94)$ & $-1.98(-2.39--1.57)$ \\
\hline Year 0-4 & 2331 & 9367 & 2027 & 6142 & $8.54(8.17-8.90)$ & $7.25(6.88-7.62)$ & $7.29(6.92-7.66)$ & $-2.08(-2.52--1.64)$ \\
\hline Year 0-5 & 2570 & 14366 & 2646 & 7583 & $9.28(8.91-9.66)$ & $7.63(7.25-8.01)$ & $7.68(7.29-8.06)$ & $-2.05(-2.51--1.59)$ \\
\hline
\end{tabular}

a Death, age-related pension and emigration.

${ }^{\mathrm{b}}$ Adjusted: matching variables (gender, age, education and income).

${ }^{c}$ Adjusted: matching variables plus (ethnicity, comorbidity and sick leave).

also carried out. Special vocational rehabilitation teams within the municipal social services were formed to ensure early interdisciplinary input and support the workdisabled to return to work in ordinary or modified jobs, thus avoiding DP. However, a reduction in granted pensions does not inform about how the work-disabled in general, and cancer patients in particular, experience these new initiatives and whether work participation has indeed increased. Therefore knowledge is needed about those work-disabled who, before 2013, would have been granted a DP but currently are offered alternative means of economic and rehabilitative support. Studies should look into this potentially vulnerable group of individuals. A cancer diagnosis often leads to new perspectives on life. For some, a re-evaluation of work life (41) may lead to a desire to change occupation or engage in activities such as volunteer work and thus, in some cases, renounce the right to social benefits (including DP). The patientcentered perspective should therefore be further explored as to whether the reform gives individuals the opportunity to engage in activities that are perceived as meaningful and improving quality of life.

In the present study, the cancer patients were more likely to receive DP than controls in both time periods. Similar findings were identified in Carlsen et al's Danish register-based study from 2008 (7), in which an increased risk of $60 \%$ and $55 \%$ in female and male cancer patients, respectively, was reported compared with matched controls. In Carlsen et al's and the present study, adjustments for known risk factors related to the workplace environment were not possible due to the register-based design. The workplace arena is considered an important stakeholder in vocational rehabilitation (42). Within Labriola's Dynamic Work Disability Model (11), management quality was identified as a possible modifying factor between person-related factors and the pathways between RTW and work termination. This was further substantiated in Feuerstein et al's review (43) where work environment factors were also found to be important in RTW studies among cancer survivors. Along with the introduction of social reforms, it is clear that the involvement of the workplace arena is a requisite for RTW (13) as the work environment needs adjustments to sustain work ability among an aging and not $100 \%$ fit workforce, in particular in mentally and physically demanding professions. The workplace arena and its effect on cancer patients' risk of DP should be further explored.

Carlsen et al (7) found that the risk of being granted DP increased with $9 \%$ and $8 \%$ per ageing year among women and men, respectively, compared with controls. We also found that the risks of DP increased with age among the cancer patients. Fortunately, few were diagnosed with cancer before the age of $40(16.8 \%)$, and fewer were granted a DP in these age groups than among those $>40$ years both before and after 2013 in the present study. Despite these encouraging results, previous studies have reported that young adults with cancer often struggle during and after the RTW process to sustain work participation $(44,45)$. Young cancer patients typically experience problems with paying attention, forgetting and keeping up with work (45). Thus, even though young adults are able to return to work, they still need support afterwards to sustain their work participation. However, effective interventions to support sustained RTW and prevent permanent work disability in young cancer patients are scarce (45), and future research is warranted.

\section{Methodological considerations}

This study has several strengths due to its populationbased design and high-quality registry data from CAR (25), DNPR (27), and DREAM $(9,28)$, which limited 
Table 3. Cumulated incidence proportions (CIP) from diagnosis , up until 5 years after, and risk differences (RD) in CIP between non-cancer and cancer groups before and after 2013 reform, stratified on matching variables.

\begin{tabular}{|c|c|c|c|c|}
\hline & \multicolumn{2}{|c|}{ Before January 2013 reform } & \multicolumn{2}{|c|}{ After January 2013 reform } \\
\hline & Cancer CIP & Adjusted for matching variables & Cancer CIP & Adjusted for matching variables \\
\hline & $\%(95 \% \mathrm{Cl})$ & RD \% (95\% Cl) & $\%(95 \% \mathrm{Cl})$ & $\mathrm{RD} \%(95 \% \mathrm{Cl})$ \\
\hline \multicolumn{5}{|l|}{ Gender } \\
\hline \multicolumn{5}{|l|}{ Female } \\
\hline Year 0-1 & & $2.75(2.58-2.91$ & & $2.04(1.76-2.32)$ \\
\hline Year 0-2 & & $6.35(6.10-6.60)$ & & $4.13(3.76-4.50)$ \\
\hline Year 0-3 & & $8.08(7.79-8.37)$ & & $5.42(5.00-5.83)$ \\
\hline Year 0-4 & & $9.16(8.84-9.47)$ & & $6.30(5.85-6.74)$ \\
\hline Year 0-5 & $13.56(13.23-13.89)$ & $9.65(9.32-9.98)$ & $8.36(7.90-8.82)$ & $6.77(6.31-7.24)$ \\
\hline \multicolumn{5}{|l|}{ Male } \\
\hline Year 0-1 & & $4.75(4.52-4.98)$ & & $3.86(3.42-4.30)$ \\
\hline Year 0-2 & & $8.31(8.00-8.61)$ & & $6.89(6.34-7.45)$ \\
\hline Year 0-3 & & $9.21(8.87-9.54)$ & & $8.11(7.51-8.71)$ \\
\hline Year 0-4 & & $9.64(9.28-9.99)$ & & $8.57(7.95-9.19)$ \\
\hline Year 0-5 & $13.54(13.18-13.90)$ & $9.78(9.42-10.15)$ & $10.58(9.95-11.22)$ & $8.81(8.18-9.45)$ \\
\hline \multicolumn{5}{|l|}{ Age (years) } \\
\hline \multicolumn{5}{|l|}{$20-29$} \\
\hline Year 0-1 & & $1.50(1.11-1.90)$ & & $0.61(0.18-1.04)$ \\
\hline Year 0-2 & & $2.92(2.37-3.48)$ & & $1.52(0.90-2.14)$ \\
\hline Year 0-3 & & $3.84(3.19-4.49)$ & & $2.36(1.62-3.10)$ \\
\hline Year 0-4 & & $4.54(3.82-5.26)$ & & $2.60(1.83-3.38)$ \\
\hline Year 0-5 & $6.17(5.40-6.94)$ & $5.08(4.30-5.86)$ & $3.37(2.58-4.17)$ & $2.79(1.99-3.59)$ \\
\hline \multicolumn{5}{|l|}{$30-39$} \\
\hline Year 0-1 & & $1.40(1.15-1.67)$ & & $0.77(0.45-1.09)$ \\
\hline Year 0-2 & & $3.45(3.04-3.85)$ & & $1.53(1.11-1.96)$ \\
\hline Year 0-3 & & $4.89(4.41-5.38)$ & & $2.23(1.73-2.73)$ \\
\hline Year 0-4 & & $5.71(5.18-6.25)$ & & $2.66(2.12-3.19)$ \\
\hline \multirow{2}{*}{\multicolumn{5}{|c|}{$40-49$}} \\
\hline & & & & \\
\hline Year 0-1 & & $3.10(2.84-3.35)$ & & $1.75(1.40-2.11)$ \\
\hline Year 0-2 & & $6.36(5.99-6.72)$ & & $3.51(3.04-3.98)$ \\
\hline Year 0-3 & & $7.94(7.52-8.36)$ & & $4.37(3.86-4.89)$ \\
\hline Year 0-4 & & $9.06(8.61-9.52)$ & & $5.02(4.47-5.57)$ \\
\hline Year 0-5 & $13.26(12.78-13.74)$ & $9.57(9.08-10.06)$ & $6.85(6.28-7.42)$ & $5.46(4.89-6.04)$ \\
\hline \multicolumn{5}{|l|}{$50-60$} \\
\hline Year 0-1 & & $4.52(4.31-4.72)$ & & $4.49(4.04-4.94)$ \\
\hline Year 0-2 & & $8.75(8.47-9.03)$ & & $8.26(7.69-8.84)$ \\
\hline Year 0-3 & & 10.04 (9.73-10.35) & & $10.02(9.39-10.65)$ \\
\hline Year 0-4 & & $10.69(10.36-11.02)$ & & $10.92(10.26-11.58)$ \\
\hline Year 0-5 & $15.32(14.98-15.66)$ & $10.81(10.47-11.16)$ & $13.57(12.90-14.25)$ & 11.30 (10.62-11.98) \\
\hline \multicolumn{5}{|l|}{ Education } \\
\hline Primary/hic & & & & \\
\hline Year 0-1 & & $5.39(5.08-5.70)$ & & $4.99(4.36-5.62)$ \\
\hline Year 0-2 & & $9.76(9.34-10.19)$ & & $8.16(7.38-8.93)$ \\
\hline Year 0-3 & & $11.50(11.03-11.97)$ & & $9.76(8.92-10.60)$ \\
\hline Year 0-4 & & $12.26(11.76-12.76)$ & & $10.55(9.67-11.43)$ \\
\hline Year 0-5 & $18.64(18.12-19.15)$ & $12.52(11.99-13.04)$ & $13.95(13.05-14.84)$ & $11.02(10.11-11.93)$ \\
\hline Vocational & & & & \\
\hline Year 0-1 & & $3.73(3.51-3.95)$ & & $2.94(2.55-3.34)$ \\
\hline Year 0-2 & & $7.51(7.20-7.82)$ & & $6.03(5.49-6.56)$ \\
\hline Year 0-3 & & $8.91(8.57-9.25)$ & & $7.38(6.80-7.96)$ \\
\hline Year 0-4 & & $9.70(9.34-10.07)$ & & 8.16 (7.55-8.78) \\
\hline Year 0-5 & $13.47(13.09-13.85)$ & $10.06(9.67-11.44)$ & $10.15(9.52-10.78)$ & 8.59 (7.95-9.22) \\
\hline Education & & & & \\
\hline Year 0-1 & & $1.97(1.48-2.46)$ & & $1.69(0.87-2.50)$ \\
\hline Year 0-2 & & $4.38(3.65-5.11)$ & & $3.42(2.33-4.51)$ \\
\hline Year 0-3 & & $5.15(4.33-5.96)$ & & $4.33(3.13-5.54)$ \\
\hline Year 0-4 & & $5.94(5.04-6.84)$ & & $4.66(3.39-5.92)$ \\
\hline Year 0-5 & 8.64 (7.71-9.57) & $6.16(5.21-7.11)$ & $5.78(4.48-7.08)$ & $4.91(3.60-6.22)$ \\
\hline Bachelor d & & & & \\
\hline Year 0-1 & & $2.01(1.76-2.26)$ & & $1.00(0.66-1.34)$ \\
\hline Year 0-2 & & $4.86(4.48-5.24)$ & & $2.57(2.08-3.07)$ \\
\hline Year 0-3 & & $5.98(5.55-6.41)$ & & $3.63(3.05-4.20)$ \\
\hline Year 0-4 & & $6.90(6.43-7.37)$ & & $4.37(3.75-4.99)$ \\
\hline Year 0-5 & $9.54(9.05-10.03)$ & $7.34(6.84-7.83)$ & $5.71(5.07-6.36)$ & $4.68(4.03-5.34)$ \\
\hline Master deg & & & & \\
\hline Year 0-1 & & $1.19(0.88-1.51)$ & & $0.69(0.27-1.11)$ \\
\hline Year 0-2 & & $3.06(2.57-3.55)$ & & $1.20(0.66-1.73)$ \\
\hline Year 0-3 & & $3.73(3.17-4.28)$ & & $1.72(1.10-2.33)$ \\
\hline Year 0-4 & & $4.34(3.72-4.95)$ & & $1.91(1.26-2.56)$ \\
\hline Year 0-5 & $6.25(5.60-6.90)$ & $4.75(4.09-5.40)$ & $2.36(1.67-3.04)$ & $2.10(1.41-2.79)$ \\
\hline
\end{tabular}


Table 3. continued

\begin{tabular}{|c|c|c|c|c|}
\hline & \multicolumn{2}{|c|}{ Before January 2013} & \multicolumn{2}{|c|}{ After January 2013} \\
\hline & Cancer CIP & Adjusted for matching variables & Cancer CIP & Adjusted for matching variables \\
\hline & $\%(95 \% \mathrm{Cl})$ & $\mathrm{RD} \%(95 \% \mathrm{Cl})$ & $\%(95 \% \mathrm{Cl})$ & $\mathrm{RD} \%(95 \% \mathrm{Cl})$ \\
\hline \multicolumn{5}{|c|}{$\begin{array}{l}\text { Income (euros per year) } \\
\leq-60395\end{array}$} \\
\hline Year 0-1 & & $3.32(-1.23-7.87)$ & & $-0.03(-0.32-0.27)$ \\
\hline Year 0-2 & & $6.79(0.33-13.26)$ & & $-0.13(-0.64-0.39)$ \\
\hline Year 0-3 & & $6.34(-0.16-12.83)$ & & $-0.16(-0.83-0.50)$ \\
\hline Year 0-4 & & $6.27(-0.21-12.76)$ & & $4.71(-4.82-14.25)$ \\
\hline Year 0-5 & $9.50(1.78-17.22)$ & $8.50(0.79-16.21)$ & $4.79(4.71-14.29)$ & $4.72(-4.80-14.25)$ \\
\hline \multicolumn{5}{|c|}{$-60394--20130$} \\
\hline Year 0-1 & & $2.27(-0.37-4.91)$ & & $-0.21(-46-0.03)$ \\
\hline Year 0-2 & & $5.88(1.60-10.16)$ & & $-2.26(-2.91-7.43)$ \\
\hline Year 0-3 & & $6.02(1.47-10.57)$ & & $1.76(-3.45-6.98)$ \\
\hline Year 0-4 & & $6.61(1.76-11.46)$ & & $1.60(-3.61-6.81)$ \\
\hline Year 0-5 & $9.74(4.72-14.76)$ & $7.63(2.48-12.78)$ & $4.99(-2.26-12.24)$ & $2.63(-4.77-10.04)$ \\
\hline \multicolumn{5}{|l|}{$-20131--1$} \\
\hline Year 0-1 & & $3.83(2.70-4.96)$ & & $2.32(-0.11-4.74)$ \\
\hline Year 0-2 & & 5. $11(3.67-6.55)$ & & $6.05(2.49-9.61)$ \\
\hline Year 0-3 & & $5.07(3.49-6.65)$ & & $6.13(2.50-9.77)$ \\
\hline Year 0-4 & & $4.82(3.12-6.51)$ & & $5.74(2.11-9.37)$ \\
\hline \multirow{2}{*}{\multicolumn{5}{|c|}{$0-20131$}} \\
\hline & & & & \\
\hline Year 0-1 & & $7.02(6.65-7.38)$ & & $6.73(5.86-7.60)$ \\
\hline Year 0-2 & & $11.74(11.26-12.22)$ & & $10.26(9.21-11.30)$ \\
\hline Year 0-3 & & $13.47(12.94-14.01)$ & & 11.91 (10.79-13.03) \\
\hline Year 0-4 & & 14.35 (13.78-14.92) & & $12.64(11.48-13.80)$ \\
\hline Year 0-5 & 22.81 (22.24-23.38) & $14.55(13.96-15.15)$ & $18.01(16.83-19.19)$ & $13.22(12.03-14.42)$ \\
\hline \multicolumn{5}{|c|}{$20132-40263$} \\
\hline Year 0-1 & & $2.60(2.45-2.75)$ & & $2.28(1.99-2.56)$ \\
\hline Year 0-2 & & $6.13(5.90-6.36)$ & & $4.77(4.39-5.16)$ \\
\hline Year 0-3 & & $7.58(7.32-7.85)$ & & $6.11(5.69-6.54)$ \\
\hline Year 0-4 & & $8.48(8.20-8.76)$ & & $6.94(6.49-7.39)$ \\
\hline Year 0-5 & 11.02 (10.73-11.31) & $8.96(8.66-9.26)$ & $8.74(8.28-9.21)$ & $7.31(6.84-7.78)$ \\
\hline \multicolumn{5}{|c|}{$40264-60394$} \\
\hline Year 0-1 & & $1.12(0.86-1.37)$ & & $0.99(0.61-1.37)$ \\
\hline Year 0-2 & & $2.71(2.31-3.10)$ & & $2.72(2.15-3.29)$ \\
\hline Year 0-3 & & $2.98(2.55-3.41)$ & & $3.48(2.85-4.11)$ \\
\hline Year 0-4 & & $3.21(2.75-3.66)$ & & $3.89(3.22-4.57)$ \\
\hline Year 0-5 & $4.96(4.49-5.43)$ & $3.36(2.89-3.84)$ & $3.68(2.98-4.37)$ & $4.19(3.49-4.89)$ \\
\hline \multicolumn{5}{|l|}{$\geq 60395$} \\
\hline Year 0-1 & & $0.76(0.37-1.15)$ & & $0.19(-0.24-0.61)$ \\
\hline Year 0-2 & & 2. $39(1.72-3.05)$ & & $0.79(0.14-1.43)$ \\
\hline Year 0-3 & & $2.89(2.14-3.63)$ & & $1.31(0.53-2.09)$ \\
\hline Year 0-4 & & $3.28(2.48-4.09)$ & & $1.42(0.61-2.24)$ \\
\hline Year 0-5 & $4.76(3.93-5.59)$ & $3.46(2.61-4.30)$ & $0.81(-0.02-1.63)$ & $1.45(0.61-2.29)$ \\
\hline
\end{tabular}

the risk of selection and information bias. However, the design prohibited adjustments for workplace- and health-related factors such as pain, anxiety and depression, which may have led to confounded risk estimates. Furthermore, the DP reform in 2013 restricted the granting of DP to persons $<40$ years, which we would have liked to adjust for in the analyses. However, our matching procedure used 10-year age strata and thus, exact age at time of diagnosis and the granting of DP was unknown. We were therefore only allowed to perform delayed entry, ie, both the cancer and control groups had survived beyond January 2013 if diagnosed with cancer prior to that time point and had not yet been granted a DP. We suspect this may be the reason for the control group's increased DP risk after January 2013, possibly leading to underestimated RD after that time point.
As social security schemes vary between countries, the transferability of our results may be limited to the Nordic region, which also has a tax-financed benefit system and is considered to offer generous systems compared with most other countries.

\section{Concluding remarks}

This Danish population-based study showed that a 2013 structural reform of the Disability Pension Act reduced the risk for cancer patients to be granted a DP. The differences between controls' and cancer patients' risk of being granted a DP were significantly reduced after the reform. However, reductions were more pronounced among the socioeconomically fortunate versus unfortunate. The impact of the reduced number of granted DP on cancer 
patients' quality of life is unknown. The patient-centered perspective should therefore be further explored as to whether the reform provides individuals the opportunity to engage in supportive activities and vocational rehabilitation that are perceived as meaningful and improving of quality of life.

\section{Acknowledgment}

We thank Merete Labriola for her valuable and constructive suggestions during the planning and development of this study.

\section{References}

1. Association of the Nordic Cancer Registries. Available from: http://www-dep.iarc.fr/NORDCAN/DK/frame.asp. [Accessed 04/26, 2016].

2. Kennedy F, Haslam C, Munir F, Pryce J. Returning to work following cancer: a qualitative exploratory study into the experience of returning to work following cancer. Eur J Cancer Care (Engl) 2007 Jan;16(1):17-25. https://doi. org/10.1111/j.1365-2354.2007.00729.x.

3. Peteet JR. Cancer and the meaning of work. Gen Hosp Psychiatry 2000 May-Jun;22(3):200-5. https://doi. org/10.1016/S0163-8343(00)00076-1.

4. Mehnert A, Koch U. Predictors of employment among cancer survivors after medical rehabilitation--a prospective study. Scand J Work Environ Health 2013 Jan;39(1):76-87. https://doi.org/10.5271/sjweh.3291.

5. Mehnert A. Employment and work-related issues in cancer survivors. Crit Rev Oncol Hematol 2011 Feb;77(2):109-30. https://doi.org/10.1016/j.critrevonc.2010.01.004.

6. Heinesen E, Imai S, Maruyama S. Employment, job skills and occupational mobility of cancer survivors. J Health Econ 2018;58:151-75. https://doi.org/10.1016/j. jhealeco.2018.01.006

7. Carlsen K, Oksbjerg Dalton S, Frederiksen K, Diderichsen $\mathrm{F}$, Johansen C. Cancer and the risk for taking early retirement pension: a Danish cohort study. Scand J Public Health 2008 Mar;36(2):117-25. https://doi. org/10.1177/1403494807085192.

8. Danish Health Authority. Cancer Pathways. Available from: http://sundhedsstyrelsen.dk/en/health/widespread-diseases/ cancer/cancer-pathways.

9. Stapelfeldt CM, Labriola M, Jensen AB, Andersen NT, Momsen AM, Nielsen CV. Municipal return to work management in cancer survivors undergoing cancer treatment: a protocol on a controlled intervention study. BMC Public Health 2015 Jul;15:720-31. https://doi. org/10.1186/s12889-015-2062-1.
10. de Boer Angela GEM, Taskila Tyna K, Tamminga Sietske J, Feuerstein M, Frings-Dresen Monique HW, Verbeek JH. Interventions to enhance return-to-work for cancer patients. Cochrane Database Syst Rev. 2011 Feb 16;(2):CD007569. https://doi.org/10.1002/14651858.CD007569.pub2.

11. Labriola M. Conceptual framework of sickness absence and return to work, focusing on both the individual and the contextual level. Work 2008;30(4):377-87.

12. Palmer E. Is Swedish pension reform the right medicine for aging Europe? J Aging Soc Policy 2002;14(1):35-52. https://doi.org/10.1300/J031v14n01_04.

13. Burdorf A. ICF from a Population Health Perspective: The Impact of Chronic Disease on Work Participation and Its Consequences for Intervention and Treatment. In: Escorpizo A, Brage S, Homa D, Stucki G, Burdorf A, editors. Handbook of Vocational Rehabilitation and Disability Evaluation. Application and Implementation of the ICF. 1st ed. Switzerland: Sringer International Publishing; 2015. p. 43.

14. Staubli S, Zweimüller J. Does Raising the Early Retirement Age Increase Employment of Older Workers? J Public Econ 2013 Dec;108: https://doi.org/10.1016/j. jpubeco.2013.09.003.

15. Nilsson K, Östergren PO, Kadefors R, Albin M. Has the participation of older employees in the workforce increased? Study of the total Swedish population regarding exit from working life. Scand J Public Health 2016 Jul;44(5):506-16. https://doi.org/10.1177/1403494816637262.

16. Farrants K, Marklund S, Kjeldgård L, Head J, Alexanderson K. Sick leave among people in paid work after age 65: A Swedish population-based study covering 1995, 2000, 2005 and 2010. Scand J Public Health 2018 May;46(3):297-305. https://doi.org/10.1177/1403494817731487.

17. The Danish Ministry of Employment. Recent labor market policy reforms. 2018; Available from: http://star.dk/da/ English/Recent-labor-market-policy-reforms.aspx.

18. Sesto ME, Faatin M, Wang S, Tevaarwerk AJ, Wiegmann DA. Employment and retirement status of older cancer survivors compared to non-cancer siblings. Work 2013;46(4):445-53. https://doi.org/10.3233/WOR-131680.

19. Roelen CA, Koopmans PC, Schellart AJ, van der Beek AJ. Resuming work after cancer: a prospective study of occupational register data. J Occup Rehabil 2011 Sep;21(3):431-40. https://doi.org/10.1007/s10926-0109274-0.

20. Cooper AF, Hankins M, Rixon L, Eaton E, Grunfeld EA. Distinct work-related, clinical and psychological factors predict return to work following treatment in four different cancer types. Psychooncology 2013 Mar;22(3):659-67. https://doi.org/10.1002/pon.3049.

21. Demark-Wahnefried W, Aziz NM, Rowland JH, Pinto BM. Riding the crest of the teachable moment: promoting long-term health after the diagnosis of cancer. J Clin Oncol 2005 Aug;23(24):5814-30. https://doi.org/10.1200/ JCO.2005.01.230.

22. Kjær T, Bøje CR, Olsen MH, Overgaard J, Johansen J, Ibfelt 
E et al. Affiliation to the work market after curative treatment of head-and-neck cancer: a population-based study from the DAHANCA database. Acta Oncol 2013 Feb;52(2):430-9. https://doi.org/10.3109/0284186X.2012.746469.

23. Luckett T, Goldstein D, Butow PN, Gebski V, Aldridge LJ, McGrane J et al. Psychological morbidity and quality of life of ethnic minority patients with cancer: a systematic review and meta-analysis. Lancet Oncol 2011 Dec;12(13):1240-8. https://doi.org/10.1016/S1470-2045(11)70212-1.

24. Amir Z, Brocky J. Cancer survivorship and employment: epidemiology. Occup Med (Lond) 2009 Sep;59(6):373-7. https://doi.org/10.1093/occmed/kqp086.

25. Gjerstorff ML. The Danish Cancer Registry. Scand J Public Health 2011 Jul;39(7 Suppl):42-5. https://doi. org/10.1177/1403494810393562.

26. Engholm G, Ferlay J, Christensen N, Bray F, Gjerstorff ML, Klint A et al. NORDCAN--a Nordic tool for cancer information, planning, quality control and research. Acta Oncol 2010 Jun;49(5):725-36. https://doi. org/10.3109/02841861003782017.

27. Lynge E, Sandegaard JL, Rebolj M. The Danish National Patient Register. Scand J Public Health 2011 Jul;39(7 Suppl):30-3. https://doi.org/10.1177/1403494811401482.

28. Hjollund NH, Larsen FB, Andersen JH. Register-based followup of social benefits and other transfer payments: accuracy and degree of completeness in a Danish interdepartmental administrative database compared with a population-based survey. Scand J Public Health 2007;35(5):497-502. https:// doi.org/10.1080/14034940701271882.

29. Rasmussen JH. The register-based evaluation of marginalised groups (DREAM-register) - code book (40); 2017. Codebook is continuously revised according to legislative changes the most recent codebook (version 43) is available from www.dst. $\mathrm{dk} / \mathrm{da} /$ TilSalg/Forskningsservice/Data/Andre_Styrelser.

30. Stapelfeldt CM, Jensen C, Andersen NT, Fleten N, Nielsen $\mathrm{CV}$. Validation of sick leave measures: self-reported sick leave and sickness benefit data from a Danish national register compared to multiple workplace-registered sick leave spells in a Danish municipality. BMC Public Health 2012 Aug;12(1):661-71. https://doi.org/10.1186/1471-2458$12-661$.

31. Charlson ME, Pompei P, Ales KL, MacKenzie CR. A new method of classifying prognostic comorbidity in longitudinal studies: development and validation. J Chronic Dis 1987;40(5):373-83. https://doi.org/10.1016/00219681(87)90171-8.

32. Thomsen RW. Diabetes Mellitus and Community-acquired Becteremia: Risk and Prognosis. Faculty of Health Sciences: Aarhus University; 2004.

33. Thygesen SK, Christiansen CF, Christensen S, Lash TL, Sørensen HT. The predictive value of ICD-10 diagnostic coding used to assess Charlson comorbidity index conditions in the population-based Danish National Registry of Patients. BMC Med Res Methodol 2011 May;11:83. https://doi.org/10.1186/1471-2288-11-83.
34. Kivimäki M, Forma P, Wikström J, Halmeenmäki T, Pentti $\mathrm{J}$, Elovainio $\mathrm{M}$ et al. Sickness absence as a risk marker of future disability pension: the 10-town study. J Epidemiol Community Health 2004 Aug;58(8):710-1. https://doi. org/10.1136/jech.2003.015842.

35. Parner ET, Andersen PK. Regression analysis of censored data using pseudo-observations. Stata J 2010;10(3):408-22. https://doi.org/10.1177/1536867X1001000308.

36. Overgaard M, Andersen PK, Parner ET. Regression analysis of censored data using pseudo-observations: an update. Stata J 2015;15(3):809. https://doi. org/10.1177/1536867X1501500313.

37. World Medical Association. World Medical Association Declaration of Helsinki: ethical principles for medical research involving human subjects. JAMA 2013 Nov;310(20):2191-4. https://doi.org/10.1001/ jama.2013.281053.

38. De Angelis R, Sant M, Coleman MP, Francisci S, Baili P, Pierannunzio D et al.; EUROCARE-5 Working Group. Cancer survival in Europe 1999-2007 by country and age: results of EUROCARE--5-a population-based study. Lancet Oncol 2014 Jan;15(1):23-34. https://doi.org/10.1016/ S1470-2045(13)70546-1.

39. Pryce J, Munir F, Haslam C. Cancer survivorship and work: symptoms, supervisor response, co-worker disclosure and work adjustment. J Occup Rehabil 2007 Mar;17(1):83-92. https://doi.org/10.1007/s10926-006-9040-5.

40. Social appeals board. Disability pension. Yearly statistics report 2016. Report in Danish [Ankestyrelsens statistikker. Førtidspension. Aarsstatistik 2016.]. 2017.

41. Tiedtke C, de Rijk A, Dierckx de Casterlé B, Christiaens MR, Donceel P. Experiences and concerns about 'returning to work' for women breast cancer survivors: a literature review. Psychooncology 2010 Jul;19(7):677-83. https://doi. org/10.1002/pon.1633.

42. Loisel P, Buchbinder R, Hazard R, Keller R, Scheel I, van Tulder $\mathrm{M}$ et al. Prevention of work disability due to musculoskeletal disorders: the challenge of implementing evidence. J Occup Rehabil 2005 Dec;15(4):507-24. https:// doi.org/10.1007/s10926-005-8031-2.

43. Feuerstein M, Todd BL, Moskowitz MC, Bruns GL, Stoler MR, Nassif T et al. Work in cancer survivors: a model for practice and research. J Cancer Surviv 2010 Dec;4(4):41537. https://doi.org/10.1007/s11764-010-0154-6.

44. Stone DS, Ganz PA, Pavlish C, Robbins WA. Young adult cancer survivors and work: a systematic review. J Cancer Surviv 2017 Dec;11(6):765-81. https://doi.org/10.1007/ s11764-017-0614-3.

45. Parsons HM, Harlan LC, Lynch CF, Hamilton AS, Wu $\mathrm{XC}$, Kato I et al. Impact of cancer on work and education among adolescent and young adult cancer survivors. J Clin Oncol 2012 Jul;30(19):2393-400. https://doi.org/10.1200/ JCO.2011.39.6333.

Received for publication: 19 December 2018 